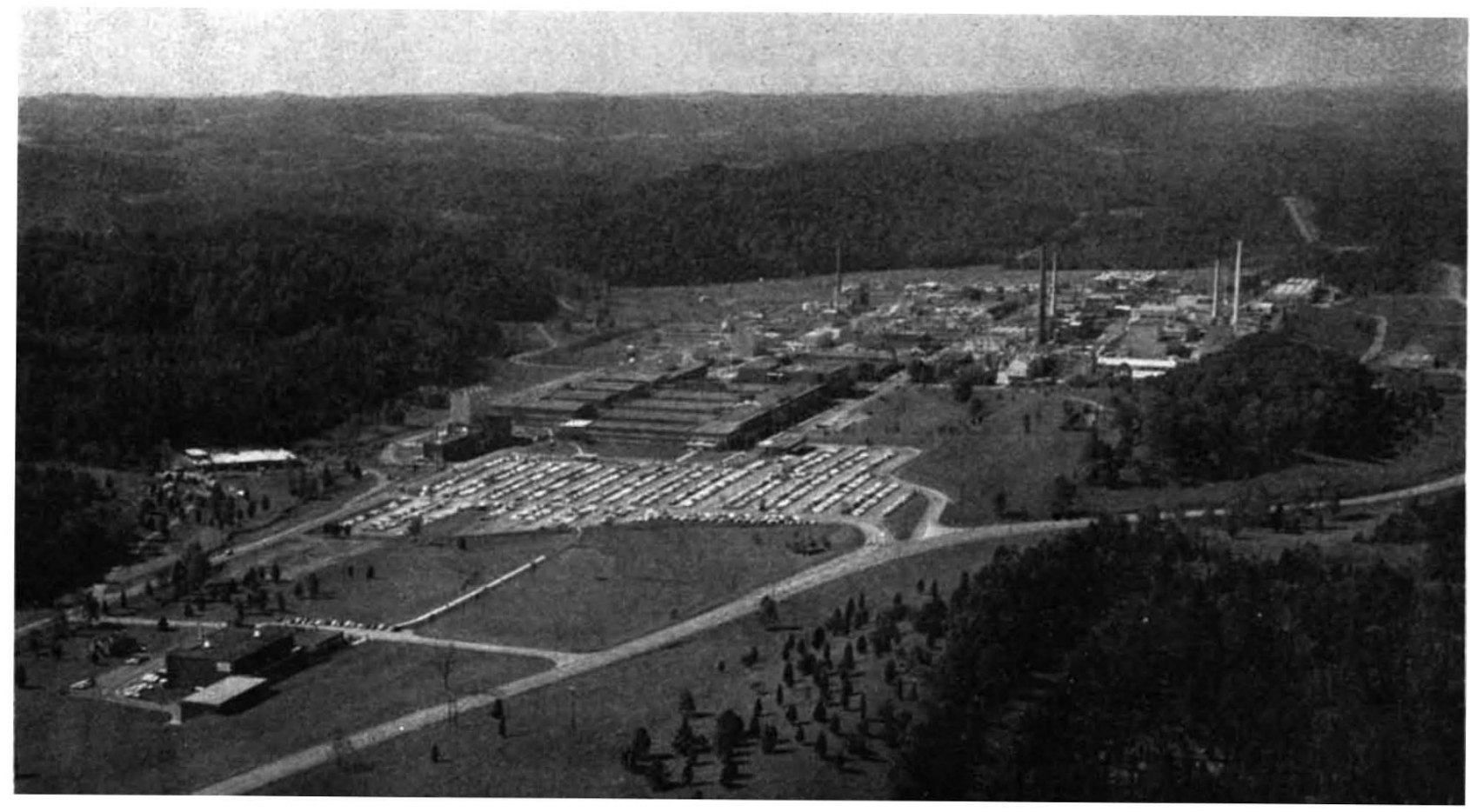

makes possible a comparatively efficient means of ionizing the neutral atoms fired at the target plasma and thus trapping them as well. Even so, it seems to be acknowledged as unlikely that, with the arrangement now being built, a density of deuterium or tritium nuclei greater than $10^{12}$ particles a cubic centimetre will be attained. This will be at least a couple of orders of magnitude below the density at which thermonuclear reactions produce more energy than the hot plasma consumes.

Like many other nuclear energy laboratories, the Oak Ridge National Laboratory is in the thick of desalination research. This is a natural accompaniment of the laboratory's view that ways of using nuclear energy are a natural part of its brief. The desalination programme, however, is less concerned with hardware than with the ways in which machinery may be used. The underlying philosophy is that improvements of agricultural practice in conjunction with irrigation offer the greatest likelihood of a dramatic improvement in the productivity of farmland. The laboratory has embarked on a programme of study in the Middle East and in the Ganges plain. Plans are being made for the establishment of a number of experimental farms each with perhaps 500 acres, a small distillation plant (not necessarily run by nuclear power) and a plentiful supply of agronomists.

Dr Weinberg is proud of the way in which his laboratory can quickly redeploy its interests in ways like this. He says that this is one of the great benefits of a multidisciplinary laboratory sustained by a hard core of enduring activity and with enough people to be flexible. In other words, he is trying to establish the view that redeployment is not a sudden reaction to adversity but, rather, a natural state of affairs for a good laboratory. Even though some of the projects which the laboratory has undertaken in the past few years-in the life sciences in particular-have not been outstandingly successful, this principle seems to have worked out well.

\section{Is a PhD Worth Having?}

A DETALLED sociological definition of the American $\mathrm{PhD}$ has been compiled by the Office of Scientific Personnel of the National Research Council in Washington, acting for the National Institutes of Health (Careers of PhDs-Academic versus Non-Academic, National Academy of Sciences, \$6). The report succeeds an earlier document, published in 1965, and is based on a survey among 10,000 people awarded $\mathrm{PhD}$ degrees between 1935 and 1960 . One of the chief objectives has been to understand the forces which distribute PhDs between academic and other jobs, but the statistics which have been collected also provide a description of the salary pattern in the scientific professions. Those in Britain who have been concerned about the large proportions of those with $\mathrm{PhD}$ degrees seeking to work in academic life-the Swann Committee, for example-may be surprised to be reminded of the academic proclivities of American PhDs.

The $\mathrm{PhD}$ graduates in the survey were chosen from the names of some 250,000 graduates on the lists of the Office of Scientific Personnel of the National Research Council. For the purposes of the survey, six groups of PhDs graduating in 1935, 40, 45, 50, 55 and 60 were sent questionnaires, and the replies were suitably weighted to account for failures to respond. For the 
group as a whole, the survey estimates that about half $(4,908)$ had always been employed in academic work, and that a quarter $(2,347)$ had always found work elsewhere. The amount of transfer between academic work and other forms of employment is small-about 15 per cent of the sample $(1,556)$ moved from academic life into the outside world while a smaller proportion (13 per cent) moved in the other direction. The table shows how these proportions vary from one field to another.

Physical scientists seem to leave academic life more readily than others, no doubt because of the competing claims of other occupations. In the past thirty years in the United States the proportion of $\mathrm{PhD}$ graduates staying on in academic life has been consistently less than a half in the physical sciences (between 41 per cent and 46 per cent) compared with a fraction of roughly two-thirds of biological scientists staying on in university life. Among the biologists, roughly 60 per cent of all $\mathrm{PhD}$ seem still to be working at universities 20 years after graduation, compared with a proportion of the physical scientists which is roughly one-third. No doubt the explanation of these differences is to be sought in the way in which postgraduate teaching in the physical sciences became, in the thirties and forties, a necessary continuation of undergraduate work and not simply a training for an academic job, which suggests that the balance may be redressed 20 years or so from now. It is entirely consistent with this observation that physical scientists should seem to be the more ready (or able) to move into and out of academic life, although there is nothing in the figures to relate the different samples to each other quantitatively-indeed, the survey confesses that it has been addressed to unduly large numbers of people working in the biological sciences.

\begin{tabular}{|c|c|c|c|c|c|}
\hline Group & $\begin{array}{c}\text { Bio- } \\
\text { sciences }\end{array}$ & $\begin{array}{c}\text { Social } \\
\text { sciences }\end{array}$ & $\begin{array}{l}\text { Phvsical } \\
\text { sciences }\end{array}$ & $\begin{array}{l}\text { Humani- } \\
\text { ties, arts, } \\
\text { profes- } \\
\text { sions }\end{array}$ & Total \\
\hline Always academic & 1,940 & 1,189 & 749 & 1,030 & 4,908 \\
\hline $\begin{array}{l}\text { Always non- } \\
\text { academic }\end{array}$ & 892 & 349 & 871 & 235 & 2,347 \\
\hline $\begin{array}{l}\text { Non-academic } \\
\text { to academic }\end{array}$ & 465 & 338 & 305 & 203 & 1,311 \\
\hline $\begin{array}{l}\text { Academic to } \\
\text { non-academic }\end{array}$ & 659 & 303 & 354 & 129 & 1,445 \\
\hline
\end{tabular}

In an attempt to discover what tempts $\mathrm{PhD}$ graduates into particular jobs, the survey has set out to compile statistics about various aspects of the career structure of professional scientists which have a gossip value of their own. According to the report, roughly half of those graduating with PhDs in the years up to 1955 were likely to have won full professorships for themselves within 10 years. Promotions have been more rapid among the groups graduating more recently. Nobody will be quite certain what to make of the fact that 90 per cent of those with $\mathrm{PhDs}$ obtained in 1935 had become full professors by 1960-patience brings its own rewards. All but 3 per cent of those with $\mathrm{PhDs}$ in the physical sciences in 1935 and electing for the academic life had become full professors by 1960 .

Salaries appear to vary very little, although such differences as there are between the various groups will do much to confirm popular prejudices of various kinds.
Thus it appears that salaries (for non-academics and the rest) were slightly greater for non-scientist $\mathrm{PhDs}$ than for scientists in the years before the war (by roughly $\$ 300$ in $\$ 2,500$ ), but that the balance was shifted in the other direction, with physical scientists well in the lead, by 1945 . One striking feature of the salary statistics is that there seems to be very little variation in the pay of PhDs of different ages after they have been at work for 15 years or more. Thus by 1963 the group graduating in 1950 had an average salary of $\$ 14,136$ - only a little less than the average salary of $\$ 14,906$ then being paid to those graduating in 1935 . The moral seems to be that "you can't get far ahead after forty".

The statistics which have been collected support the view that academic salaries in the sciences are usually less than those paid by employers other than universities. Thus in the physical sciences, academic salaries seem to start at something like 10 per cent less than salaries elsewhere; but in the social sciences there is a tendency towards parity. For all kinds of groups, the middle years are those in which academic salaries are the smallest proportion-sometimes as little as two-thirds-of those which can be earned elsewhere. In compensation, the sunset years bring comparative prosperity to academics (or penury to their contemporaries elsewhere).

Changing jobs can often be a great monetary advant. age. By switching from academic to non-academic work, American PhDs enjoy a median increase in annual salary of 14.3 per cent, compared with only 6.7 per cent for those switching in the opposite direction. These figures contrast with the situation in the United Kingdom where physicists and chemists after the age of 30 are paid less in industry than are their counterparts in the academic world (Nature, 320, 211; 1968). The general tendency seems to be that academics have spent progressively less time teaching in recent years, and slightly more time doing research. Nevertheless, PhDs switch from academic to other work in order to be able to concentrate on research. Thus it was found that people who started out in academic jobs and later switched to other work were spending more time on research than were those who remained in an academic environment. Similarly, those who started out in non-academic jobs were doing more teaching before they switched to academic work than is typical in the non-academic category; by switching they gained from 12 to 50 per cent more teaching time. The report concludes that the wish to teach or not to teach is a factor, at least partly independent of salary, that affects carcer decisions.

Although not directly correlated with career decisions, several other facts come to light. For example, those individuals who receive their support for graduate education from institutions are most likely to stay in an academic environment, and this is particularly evident in the field of humanities, arts and professions. Academics work a slightly longer week than nonacademics, and individuals who change their employer are two or three times more likely to change their field of work. Instructorships are becoming more scarce at the bottom of the academic ladder, particularly in the physical sciences, and half of the $\mathrm{PhDs}$ are now reaching full professorships 10 to 12 years after their doctorate. 